\title{
The Competency-Based Approach to Training
}

\author{
Rick Sullivan*, Noel McIntosh*
}

Throughout the world, millions of students go to school every day. These schools are part of educational systems that have existed for centuries. Students in these schools still study subjects such as science, language and mathematics in classes and courses usually scheduled to last the duration of the school year. As progression through the various subjects in school is time-based, at any given time during the year the teacher is expected to be at a specific point in the textbook of course content. While not every student may progress at the same rate, the schedule typically requires everyone to move at the same rate as the teacher. Tests are periodically administered to ensure students understand the concepts and principles. Test scores often are compared to determine the grades of the students. Unfortunately, when a student does not well on a test there often is little time for individual assistance as the teacher must move on in order to adhere to the established time schedule.

While traditional, time-based approaches to education have met with varying levels of success over the years, it is an ineffective system when the goal is to train individuals to perform specific, job-related skills. For example, an active, certified airline pilot is attending a 3-week training course to learn to fly a new type of aircraft. Will attending all sessions during the course ensure the pilot can fly the plane? Of course not! If the pilot is unable to to attend two days of the course, does this mean the pilot cannot fly the plane? Probably not. After 4 days the pilot does poorly on a written test. Should the pilot immediately fail the course or should the pilot continue with assistance and be given the opportunity to be tested again? If the pilot can pass all written tests does this indicate that the pilot can fly the plane? No! In addition to assessing knowledge, an evaluation of the pilot's skills also is required.

NORPLANT ${ }^{R}$ is the registered trademark of ThePopulation Council for subdermal levonorgestrel implants.

*JHPIEGO Corporation, Baltimore, MD, USA
Obviously, the time-based educational system used in schools and universities is not appropriate when conducting training. A more appropriate approach is competency-based training. (CBT).

\section{WHAT IS CBT?}

The unit of progression in a traditional educational system is time and is teacher-centered. In a CBT system the unit of progression is mastery of specific knowledge and skills and is learner-or participantcentered. Two key terms used in competency-based training include:

Skill-A task or group of tasks performed to a specific level of competency or proficiency which often use motor functions and typically require the manipulation of instruments and equipment (e.g., IUD insertion or Norplant ${ }^{\circledR}$ implants removal). Some skills, however, such as counseling are knowledge- and attitude-based.

Competency-A skill performed to a specific standard under specific conditions.

There appears to be substantial support for competency-based training. Norton (1987) believes that competency-based training should be used as opposed to the "medieval concept of time-based learning." Foyster argues that using the traditional "school" model for training is inefficient. ${ }^{1}$ After in-depth examinations of three competency-based programs, Anthony Watson concluded that competency-based instruction has tremendous potential for training in industry. ${ }^{2}$ Moreover, in a 1990 study of basic skills education programs in business and industry, Paul Delker found that successful training programs were competency-based. ${ }^{3}$

A competent clinician (e.g., physician, nurse, midwife, medical assistant) is one who is able to perform a clinical skill to a satisfactory standard. CBT for reproductive health professionals then is training based upon the 
participant's ability to demonstrate attainment or mastery of clinical skills performed under certain conditions to specific standards (the skills then become competencies). Norton ${ }^{4}$ defines competency-based training by describing five essential elements of a CBT system:

- Competencies to be achieved are carefully identified, verified and made public in advance.

- Criteria to be used in assessing achievement and the conditions under which achievement will be assessed are explicitly stated and made public in advance.

- The instructional program provides for the individual development and evaluation of each of the competencies specified.

- Assessment of competency takes the participant's knowledge and attitudesinto account but requires actual performance of the competency as the primary source of evidence.

- Participants progress through the instructional program at their own rate by demonstrating the attainment of the specified competencies.

\section{CHARACTERISTICS OF CBT}

How does one identify a competency-based training program? What does CBT look like? Other than a set of competencies, what other characteristics are associated with CBT? According to Foyster, Delker and Norton there are a number of characteristics of competency-based programs. ${ }^{1,3,4}$ Key charactreristics include:

- Competencies are carefully selected.

- Supporting theory is integrated with skill practice. Essential knowledge is learned to support the performance of skills.

- Detailed training materials are keyed to the competencies to be achieved and are designed to support the aquisition of knowledge and skills.

- Methods of instruction involve mastery learning and include immediate and comprehensive feedback to participants.

- Participants' knowledge and skills are assessed as they enter the program and those with satisfactory knowledge and skills may bypass training or competencies already attained.

- Flexible training approaches including large group methods, small group activities and individual study are essential components.

- A variety of support materials including print, audiovisual and simulations (models) keyed to the skills being mastered are used.

- Learning should be self-paced.

- Satisfactory completion of training is based on achievement of all specified competencies.

\section{MODELS AND SIMULATIONS IN CBT}

Models and simulations are used extensively in competency-based training courses. Airplane pilots first learn to fly in a simulator. Supervisors first learn to provide feedback to employees using role plays during training. Individuals learning to administer cardiopulmonary resuscitation (CPR) practice this procedure on a model of a human (mannequin).

Satur and Gupta developed a model in which coronary artery anastomoses may be performed and evaluated with an angioscope which facilitates skill development. ${ }^{5}$ The results of their study indicate that models are proving invaluable as a training tool. George $\mathrm{H}$. Buck in a 1991 historical review of the use of simulators in medical education concluded that; "Given the developments in this technology within the last fifty years, it is possible that the use of simulators will increase in the future, should the need arise to teach new concepts and procedures at set times to large groups of individuals" (p.24). ${ }^{6}$ Reserachers in two different experimental studies involving training people to perform breast self-examinations (BSE) compared several methods and found that using models was the most effective training method ${ }^{7,8}$. In a multicenter evaluation of training of physicians in the use of $30-\mathrm{cm}$ flexible sigmoidoscopy, Weismann et al. ${ }^{9}$ found that they were easily trained by first practicing on plastic colon models.

Norton ${ }^{4}$ believes that participants in a competencybased training course should learn in an environment that duplicates or simulates the work place. Richards ${ }^{10}$ in writing about performance testing indicates that assessment of skills requires tests using simulations (e.g., models and role plays) or work samples (i.e., performing actual tasks under controlled conditions in either a laboratory or a job setting). Finally, Delker ${ }^{3}$ in a study of business and industry found that the best approach for training involved learner-centered instruction using print, instructional technology and simulations.

\section{EVALUATION AND ASSESSMENT IN CBT}

Evaluation in traditional courses typically involves administering knowledge-based tests. While knowledge-based assessments can certainly be used in CBT to measure mastery of information, the primary focus is on measuring mastery skills. In keeping with this, Thomson ${ }^{11}$ reports that the decision to recognize a performance as satisfactory and to determine competence should be the basis for success of a compe- 
tency-based program. Moreover, Foyster ${ }^{1}$ argues that assessment in competency- based programs must be criterion-referenced with the criterion being the competencies upon which the program is based. Finally, Richards ${ }^{10}$ indicates that simulation and work sample performance tests should include a checklist or some type of rating scale.

\section{JHPIEGO'S APPROACH TO CBT}

JHPIEGO has adopted a competency-based approach to conducting clinical training in selected reproductive health practices. Based on the principles summarized in this paper, JHPIEGO's approach to CBT involves key activities which occur during the design, delivery and evaluation of training courses. These activities are summarized here and explained in detail in JHPIEGO's Clinical Training Skills for Reproductive Health Professionals and Advanced Training Skills for Reproductive Health Professionals reference manuals.

The key activities around which JHPIEGO's competency-based training is built include design, delivery and evaluation activities. The design components include:

- Identification of the specific family planning clinical skills (e.g., IUD, Norplant implants, counseling, infection prevention, or minilaparotomy) that will form the basis of a competency-based training course.

- Identification of the conditions (i.e., using models, role plays, clients) under which the skills must be demonstrated.

- Development of:

* criteria or standards to which the skills must be performed

* competency-based learning guides and checklists which list each of the steps and sequence (if necessary) required to perform each skill or activity.

* reference manuals which contain the essential, need-to-know information related to the skills to be developed by participants attending the training course

* models (e.g., Zoe pelvic model, Norplant implants training arm) to be used during training.

* training objectives which outline what the participant must do in order to master the family planning clinical skills.

* course outlines which match a variety of training methods and supporting media to course objectives.
* course syllabi and schedules which contain information about the course and which can be sent to participants in advance so they are aware of details concerning the course.

The delivery and evaluation components include:

- Administration of a precourse questionnaire to assess the participants' knowledge and attitudes about course content.

- Administration of precourse skill assessment using models ensure they possess the entry level skills (e.g., able to perform a pelvic exam if learning to insert IUDs) to sucess fully complete the course and role plays to determine the level of their communication (counseling) skills.

- Delivery of the course by a trainer/facilitator using an interactive and participatory approach.

- Transfer of skills from the trainer to the participants through clinical and counseling skill demonstrations using slide sets, videotapes, models and role plays.

- Development of the participants' skills using a humanic approach which means participants acquire the skill and then practice until competent using anatomic models and role plays.

- Practice of the skills following the steps in the learning guide until the participant becomes competent at performing the skill. During this time the trainer functions as a coach providing continuous feedback and reinforcement to participants. Only when participants are assesses and determined to be competent on a model do they work with clients.

- Presentation of supporting information and theory through interactive and participatory classroom sessions using a variety of methods and audiovisuals.

- Administration of a midcourse questionnaire to determine if the participants have mastered the new knowledge associated with the clinical skills.

- Transfer of skills from the trainer to the participants through clinical skilldemonstration using clients.

- Guided practice in providing all components of the clinical service (e.g. providing IUDs or minilap)

- Evaluation of each participant's performance (i.e, use of knowledgr, practice, attittudes and clinical skills) with clients. The evaluation by the trainer is performed using competency-based checklist. The participant is either qualified or not qualified as a result of the knowledge, attitude and skills assessments.

- Presentation of a statement of qualification which identifies the spesicif clinical service (e.g. IUDs) the individual is qualified to provide. 


\section{TRANSFER OF TRAINING}

JHPIEGO uses a four-step process to transfer specific clinical skills and knowledge from experts to service providers. These steps are part of the process of developing a family planning training system within a country. The four steps include:

- Standardizing provision of clinical methods and modifying and adapting JHPIEGO training materials as necessary

- Training service providers to competently provide these methods according to the approved standards.

- Identifying and preparing proficient service providers to function as clinical skill trainers so they are able to train other service providers.

- Identifying and preparing clinical skill trainers to function as advanced and eventually master trainers so they are able to train other clinical skill trainers, evaluate training and develop/revise course materials.

\section{SUMMARY}

Based on the concepts and principles presented in this paper, the key features of JHPIEGO's approach to training include:

- Development of competencies (knowledge, attitude and practice) are based on national standards.

- Quality of performance is built into the training process.

- Emphasis of the training is on development of qualified providers not on the number of clinicians undergoing training.

- Training builds competency and confidence because participants know what level of performance is expected, how knowledge and skills will be evaluated, that progression through training is self- paced, and that there are opportunities for practice until mastery is achieved.

\section{REFERENCES}

1. Foyster J. Getting to Grips with Competency-Based Training and Assessment. TAFE National Centre for Research and Development: Leabrook, Australia. ERIC: ED 317849, 1990.

2. Watson A. Competency-Based Vocational Education and Self-Paced Learning. Monograph Series, Technology University: Sydney, Australia. ERIC: ED 324443, 1990.

3. Delker PV. Basic Skills Education in Business and Industry: Factors for Success or Failure. Contractor Report, Office of Technology Assessment, United States Congress, 1990.

4. Norton RE. Competency-Based Education and Training: A Humanistic and Realistic Approach to Technical and Vocational Instruction. Paper presented at the Regional Workshop on Technical/Vocational Teacher Training in Chiba City, Japan. ERIC: ED 279910, 1987.

5. Satur CMR, Gupta NK. Angioscopy-Guided Training Model of Coronary Artery Anastomosis. Ann Thoracic Surg 1994; 57(5): 1343- 5 .

6. Buck GH. Development of Simulators in Medical Education. Gesnerus 1991; (48): 7-28.

7. Campbell H et al. Improving Physicians' and Nurses' Clinical Breast Examination: A Randomized Controlled Trial. Amer Prev Med 1991; 7(1): 1-8.

8. Assaf AR et al. Comparison of Three Methods of Teaching Women How to Perform Breast Self-Examination. Health Education Quaterly 1985; 259-72.

9. Weissman GS et al. Multicenter Evaluation of Training of Non- Endoscopist in 30-CM Flexible Sigmoidoscopy. Cancer J Clin 1987; 37(1): 26-30.

10. Richards B. Performance Objectives as the Basis for Criterion-Referenced Performance Testing. J Industr Teacher Educ 1985; 22(4): 28-37.

11. Thomson P. Competency-Based Training: Some Development and Assessment Issues for Policy Makers. TAFE National Centre for Research and Development: Leabrook, Australia. ERIC: ED 333231, 1991. 